УДК 697.331

\title{
Предпосылки использования влияния теплообмена на потерю тепловым потоком, пересекающим ограждение
}

\author{
Н. А. Прусенков \\ Одесский национальный политехнический университет, пр. Шевченко,1, г. Одесса, 65044, Украина
}

\begin{abstract}
Широко известны и используются в различных процессах системы регулирования температур на поверхностях многослойных ограждающих конструкций (МОК), обеспечивающчие достижение разных и даже противоположных иелей: поддержание заданной температуры внутренней поверхности МОК, ограничиваюшихся нормированием потерь при постоянных сопротивлениях переходу тепла через слои (замкнутые); интенсификацию обмена теплом с пространством через поверхности МОК, изменением температуры теплоносителя при эксплуатации (подвижные). При этом действующая ДБН рекомендует замену в расчетах перехода тепла через МОК на теплообмен в тепловой оболочке зданий, что противоречит постулатам о постоянстве и исключительности замкнутых конструкиий ограждений требуя модернизации нормативно-теоретической базы их создания. Регулирование характеристик составляющих замкнутых и подвижных систем, объединенных в единую эволюционную на принципах суперпозиционирования и дистрибуции результатов их взаимодействия, обеспечивает проявление эксергетических свойств взаимодействия теплообмена и подаваемого при переходе тепла, отсутствующих у систем, для взаимодействия которых созданы условия. Это обеспечивает формирование новой цели, не достижимой при локальной эксплуатации каждой из взаимодействующих систем. Энергетический баланс объединения этих систем стимулирует эволюцию эксплуатационного режима, создавая эксергетическую систему взаимодействия замкнутых и подвижных потоков, достигая иель публикации. Представленный результат доказывает иелесообразность дополнения действующих нормативов указаниями, регламентирующими исключение выброса энергии через наружные поверхности ограждений.
\end{abstract}

Ключевые слова: Взаимодействие; Переход тепла; Система; Теплоноситель; Теплообмен; Эксергия.

\section{Передумови використання впливу теплообміну на втрату тепла струмом, що перетинає огорожу}

\section{М. О. Прусенков}

Одеський національний політехнічний університет, пр. Шевченка, 1, м. Одеса, 65044, Україна

\begin{abstract}
Широко відомі і використовуються в різних процесах системи регулювання температур на поверхнях багатошарових конструкиій огорож, щчо забезпечують досягнення різних і навіть протилежних иілей: підтримка заданої температури внутрішньої поверхні багатошарової конструкиії огорожі, ш⿻ обмежуються нормуванням втрат при постійних опорах переходу тепла через шари (замкнуті); інтенсифікація обміну теплом з простором через поверхні багатошарової конструкиії огорожі, зміною температури теплоносія при експлуатаціі (рухомі). При иъьому діюча ДБН пропонує заміну в розрахунках переходу тепла через багатошарову конструкцію огорожі на теплообмін у тепловій оболонці будівель, щуо суперечить постулатам про сталість $і$ винятковість замкнутих конструкцій огорож та вимагає модернізацї нормативно-теоретичної бази їх створення. Регулювання характеристик складових замкнутих і рухомих систем, об'єднаних у єдину еволюиійну на принципах суперпозічіонування і дистрибуиії результатів їх взаємодії, забезпечує прояв ексергетичних властивостей взаємодї теплообміну і надання енергї при переході тепла, відсутніх у систем, для взаємодії яких створені умови. Це забезпечує досягнення нової мети, яка не досяжна при локальній експлуатачї кожної з взаємодіючих систем. Енергетичний баланс об'єднання ичих систем стимулює еволюиію експлуатаційного режиму, утворюючи ексергетичну систему взаємодії замкнутих і рухомих струмів, для досягнення мети публікації. Наведений результат доводить доцільність доповнення діючих нормативів вказівками, ияо регламентують виключення викиду енергії через зовнішню поверхню огорожі.
\end{abstract}

Ключові слова: Взаємодія; Перехід тепла; Система; Теплоносій; Теплообмін; Ексергія. 


\section{1 Выброс тепла в потоке, пересекающем мно- гослойную ограждающую конструкцию. Цель публикации}

Особенностью методических указаний для расчета потерь энергии потоком тепла, пересекающим многослойную ограждающую конструкцию (МОК), узаконенной ДБН В.2.6-3:2006 «Тепловая изоляция...»[1], является использование основ, изложенных в СНиП-II-3-79** (ф.ф. 3-5 [2]). Они базируются на учете влияния удельных термических сопротивлений всех замкнутых слоев МОК (Rx), составляющих термическое сопротивление всего замкнутого ограждения $\left(R\right.$ мок $\left.=\sum R \mathrm{x}\right)$. Особое внимание в этих документах уделено оценке замкнутой воздушной прослойки Rзвп (Приложение 4 [2] или Таблица И1 [1]), влияющей на потери энергии в тепловом потоке, пересекающем МОК. При этом указанные нормы пренебрегают подвижностью воздушной среды. Аналогичные теоретические основы использованы в «Рекомендациях по проектированию навесных фасадных систем с вентилируемым воздушным зазором...» [3]. Документы [1-3] ограничиваются учетом затрат и поступлений при переходе тепла в энергетическом потоке, пересекающем МОК, для преодоления термического сопротивления ограждения замкнутых составляющих слоев $\left(R\right.$ мок $=R$ мок3 $\left.=\sum R \times 3\right)$. Они формируют конструкцию ограждения, для создания простейшей системы, поддерживающей заданную температуру на внутренней поверхности МОК $\left(t_{\mathrm{B}}=\right.$ const $)$ при единственном источнике энергии - тепловом потоке через внутреннюю поверхность МОК $(Q$ в). Влияние прочих потерь и поступлений энергии на переход тепла через ограждающую конструкцию считается нежелательным, малозначимым и независящим от рассчитываемого источника тепла МОК. Определяя тепловую нагрузку на систему, поддерживающую температуру внутренней поверхности многослойного ограждения, прочими источниками и потерями пренебрегают [1,2,3,]. Базирование расчетов перехода тепла через МОК на законе Фурье [4,5], при неизменном термическом сопротивлении замкнутых $(R$ мокз $=$ const $)$ слоев, обязывает считать постоянными потери на переход теплового потока $(Q$ мокз = const) через ограждение, при заданной температуре его внутренней поверхности и нормативном значении температуры снаружи $\left(t_{\mathrm{H}}=t\right.$ нпрфз). Авторы перечисленных документов пытаются ограничить и узаконить однозначность нормативов удельных термических сопротивлений и затрат на их преодоление в период эксплуатации ограждений.

ДБН не запрещает избытки фактического (ф) тепла в замкнутом (з) потоке, пересекающем замкнутую МОК

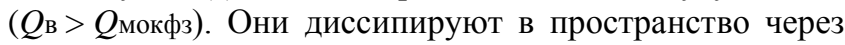
ее поверхность. Выбросы избытков энергии вызваны постоянными изменениями фактического перепада

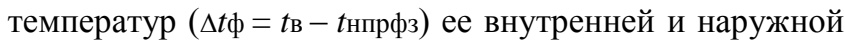
$t$ нпрфз поверхностей. Узаконенное ДБН превышение фактическими значениями температуры наружного пространства норматива, установленного для наружной поверхности ( $t$ нпрфз $\left.>t_{\mathrm{H}}\right)$ при эксплуатации, сравнительно с расчетными равенством $\left(t_{\text {нпрфз }}=t_{\mathrm{H}}\right)$, регламентирует постоянное занижение величины фактического перепада температур на поверхностях, сравнительно с нормативным $\left(\Delta t_{\text {нпрф}}=t_{\mathrm{B}}-t_{\mathrm{H}} \phi t_{\mathrm{B}}-t_{\mathrm{H}}=\Delta t\right)$, стимулируя выброс и диссипацию избытков в наружном пространстве. Тогда фактические потери на переход потока $Q$ мокфз должны оказаться, при эксплуатации, не больше поступлений, предусмотренных системой $\left(Q_{\text {мокфз }}<Q_{\text {в }}\right)$ [1-4].

Отечественная норма ДБН [1], даже после уточнения в 2013 году, и предшествующие СНиП [2] ограничиваются учетом перехода тепла через ограждения, выполненные исключительно из замкнутых слоев (см. Приложение Б ДБН [1]). Воздушную прослойку в них умудрились считать элементом термического сопротивления замкнутого вентиляционного потока $\left(R_{\mathrm{B}}=R_{3 в п}\right)$ [1-3]. К сожалению, в такой системе, поддерживающей постоянство температуры на внутренней поверхности ограды и энергии потока ( $t_{\mathrm{B}}=$ const $и$ $Q_{\text {в }}$ const), пересекающего ограждение, а так же его мощность $\left(N_{\mathrm{B}}=\mathrm{const}\right)$, практически не зависят от фактических температур в пространстве и на наружной поверхности. Они регламентированы допустимыми перепадами температур $\left(\Delta t=t_{\mathrm{B}}-t_{\mathrm{H}},{ }^{\circ} \mathrm{C}\right)$ и конструктивными решениями, неизменными в период эксплуатации $(R \mathrm{x}, \delta \mathrm{x}, \lambda \mathrm{x})$.

Выбросы избытков ( $Q$ выб, Дж) энергии возникают из-за занижений фактического перепада температур поверхностей $\mathrm{MOK}\left(\Delta t \phi=t_{\mathrm{B}}-t_{\mathrm{H} 3},{ }^{\circ} \mathrm{C}\right)$, сравнительно с нормативным значением $\left(\Delta t=t_{\mathrm{B}}-t_{\mathrm{H}},{ }^{\circ} \mathrm{C}\right)$. Предусмотренное ДБН превышение температурой наружного пространства норматива, установленного для наружной поверхности МОК $\left(t_{\text {нз }}>t_{\mathrm{H}}\right)$ при эксплуатации, сравнительно с их расчетными равенством, регламентирует занижение величины фактического перепада температур поверхностей ограждения, сравнительно с нормативным $(\Delta t \phi<\Delta t)$, стимулируя выброс избытков в пространство.

Фактические потери тепловым потоком на переход замкнутых слоев ( $Q \sum$ мокз, Дж) нормируются ДБН, при обеспечении эксплуатации поступлением тепла $Q_{\text {в в }}$ количестве, превышающем потери $\left(Q \sum\right.$ мокз < $\left.\mathrm{Q}_{\text {в }}\right),[1-4]$, что формирует выброс:

$$
Q \sum \text { выбз }=Q \text { в }-Q \sum \text { мокз } .
$$

Задача уменьшения или исключения выброса избытков через наружную поверхность замкнутого слоя МОК в период эксплуатации не решается способами, перечисленными этими документами. В них потери тепла просто нормируются, регламентируя допустимый предел [1-4]. В неизменном температурном режиме эксплуатации замкнутой МOK ( $t_{\mathrm{B}}=$ const, $t_{\mathrm{H}}=$ const $\left.<t_{\mathrm{H} 3}\right)$ за определенный период времени $t_{\text {cек }}$ выброс энергии через ее наружную поверхность $Q$ выбз

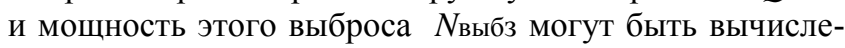
ны как разности регламентированных нормами поступлений, пересекающих внутреннюю поверхность $\left(Q_{\mathrm{B}}=N_{\mathrm{B}} x t\right.$ сек$)$, и потерь на преодоление термических сопротивлений, установленных нормами для замкнутых многослойных ограждающих конструкций, согласно закону Фурье и действующей ДБН $Q$ мокз $/\left(t_{\text {cек }} \cdot F\right)=N_{\text {мокз }} / F=\Delta t$ ф $/ R$ мокз и $\quad \Delta t \phi=t_{\mathrm{B}}-t_{\mathrm{H} 3}<\Delta t=t_{\mathrm{B}}-t_{\mathrm{H}}$ [1-4]: 


$$
N_{\text {выбз }}=N_{\mathrm{B}}-N \sum \text { мокз, } \mathrm{BT}
$$

При постоянстве температуры и поступления энергии через внутреннюю поверхность МОК в потоке, преодолевающем постоянное термическое сопротивление замкнутого ограждения $\left(\sum R \mathrm{x}=\mathrm{const}\right)$, температура наружной поверхности замкнутой МОК должна быть не меньше фактической температуры наружного пространства $\left(t_{\mathrm{H}}=\right.$ const $\left.>t_{\mathrm{H} \phi}\right)$. Уменьшение или исключение фактического выброса через поверхность замкнутого ( $Q$ выбфз) наружного слоя МОК при эксплуатации формирует экономичность системы [1] ( $Q_{\text {выбз }}$ $=Q_{\text {выбфз }}=Q_{\text {выбфз }}=0$ ).

Цель публикации - модернизация системы, регулирующей выброс тепла в потоке, пересекающем ограждение, исключением потери энергии через его наружную поверхность, способом, не использованным ранее при эксплуатации.

Навсегда устранить выброс через наружную поверхность МОК $\left(Q_{\text {выбфз }}=0\right)$ возможно, обеспечив в период эксплуатации постоянное равенство фактических температур поверхности $t$ нф и окружающего про-

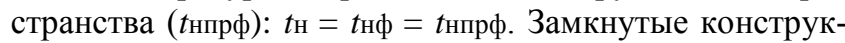
ции МОК такого регулирования не предусматривают [1-5].

\section{2 Потери тепла в потоке через замкнутую МОК согласно ДБН}

Поддерживая постулаты о постоянстве расчетных характеристик замкнутых слоев $(R \times 3, \delta$ хз, $\lambda$ хз $)$, ДБН [1] вводит, казалось бы просто, вместо термина «Многослойная Ограждающая Конструкция» (МОК), понятие «Тепловая Оболочка Здания» (ТО3). Но, в специально добавленном к ДБН [1] Приложении Н (справочном) указывается, что расчетное значение удельных потерь тепла в период отопления определяют по формуле

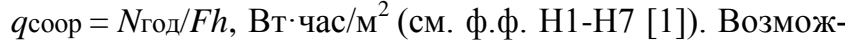
но, для исключения промахов и использования в проектах необоснованного справочного приложения в расчетах потерь тепла, даже единицы измерения характеристик сформулированы и представлены в «нестандартной» системе единиц измерения, что усложняет оценку актуальности новшества в этом приложении ДБН. Приложение $\mathrm{H}$ (справочное) рекомендует использование подвижных сред в ТО3, что противоречит постулатам этой же нормы [1]. Допустимость включения подвижного слоя в состав МОК следует закрепить нормативно и законодательно. Необходима мотивированная модернизация действующей ДБН.

Рекомендация ДБН (см. Приложение Н (справочное) [1]) воспринимается альтернативой указанным нормам и противопоставлением расчету перехода потока в подвижном слое замкнутой воздушной прослойки. Она весьма перспективна для регулирования фактического выброса тепла через наружную поверхность МОК $Q$ выбф и фактической температуры на ее наружной поверхности $t$ нф при эксплуатации.

Представляя потери тепла потоком, пересекающим МОК, частью затрат ТО3, которые нормируются $q$ соор, заменяют перспективы постоянного регулирования вы- броса $Q$ выбф через наружную поверхность МОК на нормирование поступлений, осредняя их за весь отопительный период. При этом методики расчетов, ориентируясь на формирования запаса надежности и поддержание нормативного потенциала существующей системы, компенсирующих ее несовершенство, регламентируют превышение нормативных поступлений, сравнительно с фактическими выбросами ( $q$ соор $>Q_{\text {выбф } / F)}$ [1-4]. Кроме того, действующая норма пренебрегает учетом затрат источника на перенос и поступление подвижной составляющей среды [5]. Необходима модернизация теоретических основ работы существующей системы эволюцией методики для исключения выброса избытков энергии в наружное пространство МОК.

\section{3 Поступление тепла и энергии в подвижном слое конструкции}

Поступления и перемещения потоков тепла в подвижных слоях от дополнительных источников широко используются в теплообменных аппаратах и системах отопления для компенсации потерь энергии теплоносителями [6-10].

При расчетах потерь энергии потоком в подвижной среде Qп не следует забывать, что затраты на ее транспортирование и удаление осуществляются за счет энергии, получаемой от дополнительного источника. Фактические (ф) избытки тепла, поступившего в потоках МОК, могут выбрасываться через ее наружную поверх-

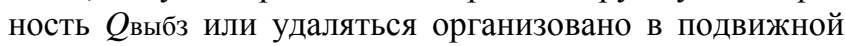
среде потоков в подвижном слое $Q$ удап:

$$
Q \sum \text { выб = } Q \text { выбз } Q \text { удап, }
$$

где: Q $\Sigma$ выб, Дж - суммарные выбросы (избытки) поступления в МОК от источников; Qвыбз, Дж - выброс в потоке через наружную поверхность замкнутого слоя; Qудап, Дж - удаление в среде подвижного МОК.

Для замкнутых МОК, согласно ДБН, унос тепла в средах слоев не предусмотрен - Qудап $=0$.

Поступления в подвижной среде Qп не учтены действующей нормой для замкнутых слоев как поступления тепла, но при постоянстве теплосодержания в подаваемом потоке могут регулировать тепловые потоки в МОК изменением скорости и расхода теплоносителя в подвижном слое.

Определение затрат на перемещение транспортирующей среды - это стандартная задача пневмотранспорта. При постоянном теплосодержании подаваемой среды, поступление тепла в МОК может регулироваться расходом и скоростью подвижного потока. В этой публикации, затраты энергии внешним (дополнительным) источником на перемещение транспортирующей среды $(Q$ мехп $=0)$ не учитываются как известные для упрощения решаемой задачи, ограничиваясь только оценкой потерь тепла. Но включение их в баланс эволюционной эксергетической системы обязательно [4-6]. Помимо затрат механической энергии $Q$ мехп или ее мощности $N$ мехп на перемещение среды, несущей тепло в тепловом потоке, дополнительный источник формирует теплопоступления в среде подвижного слоя $Q_{\text {тепп и }} N_{\text {тепп }}$ [5-9]: 


$$
Q_{\Pi}=Q_{\text {мехп }}+Q_{\text {тепп. }}
$$

Создание единой системы регулирования энергетического баланса ограждения, формируется эксергетическим взаимодействием теплоэнергетической и механической систем:

$$
Q \sum \text { пос }=Q_{\Pi+}+Q_{\text {в }}
$$

где $Q \sum$ пос, Дж - суммарные поступления тепла и энергии МОК от двух источников;

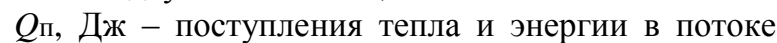
подвижного слоя МОК;

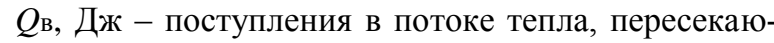
щем замкнутые слои МОК.

Поступление тепла в подвижном слое эволюцион-

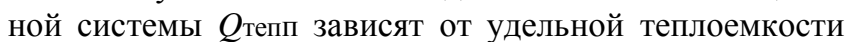
подвижной среды $\left(\mathrm{C} v\right.$, Дж/ $\left(\mathrm{M}^{2} \cdot \mathrm{K}\right)$, перепада $\left(\Delta T=t_{\text {пв }}-\right.$

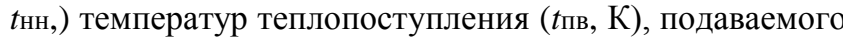
в среде подвижного потока, и наружного пространства $\left(t_{\text {нн, }} \mathrm{K}\right)$, при известном расходе теплоносителя, за определенное время $\left(L=W \cdot t\right.$ сек, $\mathrm{M}^{3} /$ сек $)$ :

$$
Q_{\text {тепп }}=\mathrm{C}_{v} \cdot \Delta T \cdot L \cdot t \text { сек } .
$$

Конструктивное и технологическое взаимодействие замкнутого теплового потока $Q$ в, пересекающего МОК через внутреннюю поверхность, с подвижным

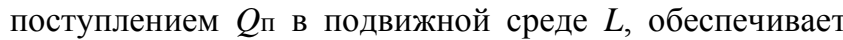
это эволюционное развитие взаимодействием систем теплоизоляции и теплообмена, проявляющее новые свойства, позволяющие исключить выброс тепла через наружную поверхность в окружающее пространство.

Регулирование теплопоступления в подвижном слое $Q$ теп должно учитывать технологические требования и обеспечивать работоспособность МОК.

Фактически поступления тепла и энергии в дополнительном подвижном слое формируют средства для достижения цели данной публикации.

\section{4 Эволюция систем регулирования наружной температуры МОК}

Идея модернизации системы, поддерживающей температуру на внутренней поверхности МОК, предусматривает взаимодействие замкнутых, существующих согласно нормам [1-4], и подвижных, созданных дополнительно, по аналогии с теплообменниками [5-9], слоев, устраняющих выброс тепла в окружающее пространство через наружную поверхность, в период эксплуатации МОК.

Взаимодействие узаконенной нормативными документами системы теплоизоляции (перехода тепла через МОК) [1-5] с системой теплообмена в подвижных средах [4-9], стимулировало проявление свойств эксергетических систем, отсутствующих у взаимодействующих [5-9].

Обеспечив регулируемые компенсационные поступления в период эксплуатации [10] возможно исключить выброс избытков поступлений через наружную поверхность ограждения, что позволяет прогнози- ровать проявление ряда технико-экономи-ческих преимуществ и совершенствований в созданной эволюционной системе [4-6].

Регулирование расхода тепла в подвижном слое должно учитывать необходимость взаимодействия при обеспечении работоспособности подвижной, замкнутой и транспортной составляющих системы модернизированной в эксергетическую. Например: при указанной модернизации, на поверхностях подвижного слоя в ней не допускается конденсация влаги $\left(\mathrm{t}_{\mathrm{n}}>\tau_{\mathrm{Bл},}{ }^{\circ} \mathrm{C}\right)$. Соответственно, средняя температура среды, уносимой подвижным потоком, определяется половиной суммы температур на поверхностях этого слоя, а перепад ее с температурой наружного пространства составляет:

$$
\Delta T_{\mathrm{cp}}=\left(t_{\mathrm{H \Pi}}+t_{\Pi \mathrm{B}}\right) / 2-\mathrm{t}_{\mathrm{H}} .
$$

где $\Delta \mathrm{T} c p,{ }^{\circ} \mathrm{C}-$ перепад средней температуры в подвижном слое МОК;

$t_{\text {нп, }}{ }^{\circ} \mathrm{C}$ - температура наружной поверхности подвижно слоя МОК;

$t_{п в},{ }^{\circ} \mathrm{C}$ - температура внутренней поверхности подвижного слоя МОК;

$t_{\text {нн }},{ }^{\circ} \mathrm{C}$ - температура пространства с наружной стороны МОК.

При соответствующих расходе среды теплоносителя L и прочих указанных в публикации данных легко рассчитать потери энергии, удаляемые в подвижном потоке:

$$
Q \mathrm{elfg}=\mathrm{C} v \cdot \Delta T \mathrm{ch} \cdot L \cdot t \mathrm{ctr}
$$

Это необходимо для составления энергетического баланса модернизированной системы при решении ряда практических задач.

\section{Выводы}

1. Действующая нормативная база декларирует постоянство термических сопротивлений, исключая регулирование температур и потерь энергии МОК при эксплуатации [1-3].

2. Существующие методики расчетов и создания МОК ограничиваются поддержанием нормативов температур внутренних поверхностей и пренебрегают целесообразностью исключения выброса в потоках, их пересекающих [3-6].

3. Целесообразна и перспективна модернизация систем регулирования температуры МОК, предусматривающая взаимодействие замкнутых и подвижных потоков за счет компенсационных поступлений от внешних источников.

4. Определение подвижного потока теплоносителя в подвижном слое МОК, формирующее сопротивление переходу теплового потока через него, как указано в общеизвестной методике, использованной действующими нормами, надо доказывать [1-5]

5. Формулы, использованные при организации взаимодействия систем, обеспечивающих взаимодействие перехода тепла и теплообмена между соприкасающимися поверхностями МОК, иллюстрируют взаимосвязь теоретических основ этих процессов и перспективу эво- 
люции, обеспечивающую регулирование температур на их поверхностях.

6. Цель публикации достигается обеспечением взаимодействия свойств, проявляемых составляющими МОК, при осуществлении перехода тепла и теплообмена между ними, при эксплуатации [4-10].

7. Необходимы дополнения действующих нормативов, регламентирующие режимы взаимодействия в модернизированной системе замкнутых и подвижных слоев [1-10].

\section{Литература}

1. ДБН В.2.6-31:2006 (ЗМІНИ-2013) Теплова ізоляція будівель. - Київ: Мінбуд України, 2014. - 65 с.

2. СНиП 11-3-79** Строительная теплотехника. - М.: Госстрой СССР, 1992.

3. Рекомендации по проектированию навесных фасадных систем с вентилируемым воздушным зазором для нового строительства и реконструкции. - М.: Москомархитектуры, 2002. - 104 с., ил.

4. Тихомиров К. В. Теплотехника, теплогазоснабжение и вентиляция. - М.: Стройиздат, 1981. - 272с., ил.

5. Соколов Е. Я., Бородянский В. М. Энергетические основы трансформации тепла и процессов охлаждения.

- М.: Энергоиздат, 1981. - 320 с., ил.

6. МПК15, кл. F24-28 «Теплообменные аппараты».

7. Кузич Р. В. и др. Конструкция наружной стены с тепловым и теплоизоляционным барьерами. - Патент UA 411188, E04B 01/00, 10.2009.

8. Орлов Д. П. Способ отопления зданий. - AC RU 2301944C1, F24D15/00, 01.2006.

9. Бродянский В. М. Эксергетический метод термодинамического анализа. - М.: Энергия, 1973. - 296 с.

10. Прусенков Н. А. Компенсация потерь тепла «подвижным» слоем ограждений. - Холодильная техника и технология, №1, 2012. - с. 46-49.

Отримана в редакції 15.03.2017, прийнята до друку 06.06.2017

\title{
Background of the Heat Transfer Influence Utilization for Heat Losses by Current which Crosses Enclosure
}

\author{
N. A. Prusenkov \\ Odessa National Polytechnic University, av. Shevchenko, 1, Odessa, 65044, Ukraine
}

The systems of temperatures regulation on the surfaces of multi-layered enclosing structures (MES), providing the achievement of different and even opposite aims: a) maintenance of the predetermined temperature of MES internal surface, which is bounded by the normalization of losses at constant resistances to the heat transfer through the layers (closed); б) intensification of exchange by heat with space through MES surfaces, by the change of temperature of coolant-moderator during exploitation (movable) are well-known and used in the different processes. At the same time, the acting DBN recommends a replacement in calculating of heat transfer through the MOS for heat exchange in thermal envelope of buildings, that contradicts the postulates of the constancy and exclusivity of enclosed enclosure designs requiring the modernization of the regulatory and theoretical basis for their creation. The regulation of the characteristics of closed (a) and mobile (b) systems components, combined into a single evolutionary one based on the principles of superposition and distribution of their interaction results, ensures the manifestation of the exergic properties of the interaction of heat exchange and heat supplied during the transition, which are absent in systems for the interaction of which conditions are created. This ensures the formation of a new goal that is not achievable at a local operation of each of the interacting systems. The energy balance of the unification of these systems stimulates the evolution of the operational mode, creating an exergic system of closed and mobile flows interaction, achieving the goal of publication. The presented result proves the expediency of supplementing the current standards with instructions governing the elimination of energy release through the outer surfaces of enclosures.

Keywords: Interaction; Heat Transition; System; Coolant-Moderator; Heat Exchange

\section{References}

1. DBN B. 2.6-31:2006 (ZMINY-2013) Teplovaya izolyatsiya zdaniy $i$ sooruzheny. K: Minstroy Ukrainy "Ukrstroyinform", 2014, 65 p. (in Ukrainian)

2. SNiP II-3-79** (1986) Stroitelnay teplotehnika. M.: Gosstroi, 32 p. (in Russian)

3. Rekomendatsii po proekirovaniy navesnih fasadnyh sistem $s$ ventiliruymim vozdushnym zazorom dlya stroi-tel'stva i rekonstruktsii zdaniy. (2002). M: Moskomarkhitektura, 104 p. (in Russian)

4. Tikhomirov K. V. (1981) Teplotekhnika, teplogazosnabzhenie i ventiliatsia. M.: Stroyizdat, 272 p. (in Russian)

5. Sokolov E. Y., Brodianskii V. M. (1981). Energeticheskie osnovy transformatsii tepla i protscessov okhlazhdeniia. Moskow: Energoizdat, 320 p. (in Russian)
6. MPK15 - kl. F24-28 «Teploobmenyie apparaty».

7. Kuzich R.V. et al. Patent na korisnu model $41188 \mathrm{U}$ VGR EO4B 1/00, Konstrukcii zovnishnei stiny budivli z teplovym ta teploinerciinym barieramy, 2009 (in Ukrainian) 8. Orlov D. P. Sposob otopleniia zdanii. AS RU 2301944 C1, F24D 15/00, 01.2006 (in Russian)

9. Brodianskii V. M. (1973) Eksergeticheski metod termodinamicheskogo analiza. M.: Energiy, 296 (in Russian)

10. Prusenkov N. A. (2012) Heat loss compensation in «mobile» protection layer. Refrigeration engineering and technology, 1(135), 46-48 (in Russian)

Received 15 March 2017

Approved 06 June 2017 Available in Internet 03 July 2017 